\title{
DIREITOS CULTURAIS E TOLERÂNCIA: UM DIÁLOGO ENTRE HABERMAS E FORST COMO PRESSUPOSTO PARA UMA TEORIA DA JUSTIÇA
}

\section{Cultural rights and tolerance: a dialogue between Habermas and Forst as a support for a theory of justice}

Los derechos culturales y la tolerancia: un diálogo entre Habermas y Forst como hipótesis para uma teoría de la justicia

\begin{abstract}
"Letztlich können die privaten Rechtssubjekte nicht in den Genu $\beta$ gleicher subjektiver Freiheiten gelagen, wenn sie sich nicht selbst, in gemeinsamer Ausübung ihrer politischen Autonomie, über berechtigte Interessen und Maßstäbe klarwerden und auf die relevanten Hinsichten einigen, unter denen Gleiches gleich und Ungleiches ungleich behandelt werden soll".

"Enfim, os sujeitos jurídicos privados não podem chegar ao gozo das mesmas liberdades subjetivas se eles mesmos, no exercício comum de sua autonomia política, não tiverem clareza sobre interesses e padrões justificados, e não chegarem a um consenso sobre aspectos proeminentes, sob os quais o que é igual deve ser
\end{abstract}

\footnotetext{
1 Professor do PPG em Direito na Universidade de Passo Fundo (UPF), e em Filosofia do Direito; pós-Doutor em Direito pela Universidade Regional Integrada do Alto Uruguai (URI), Santo Ângelo, RS; Doutor em Ciências Jurídicas e Sociais pela Universidade Federal Fluminense(UFF), Rio de Janeiro, RJ; graduado em Direito e Filosofia pela UPF. https://orcid.org/0000-00026543-0007. E-mail: marcio@upf.br.
} 
tratado como igual e o que é diferente deve ser tratado como diferente". Jürgen Habermas

\title{
Resumo
}

Por meio de uma análise reconstrutiva da filosofia político-jurídica de Jürgen Habermas e de Rainer Forst, bem como com auxílio de literatura secundária, são analisados os conceitos de direitos culturais e tolerância. O objetivo da presente pesquisa é visualizar como Habermas e Forst desenvolvem os referidos conceitos. Para este fim, o artigo é dividido em duas seções, a partir de uma justificativa introdutória da investigação dos objetivos traçados. A primeira seção trata da questão que envolve os direitos culturais, seu significado, evolução e maneira de efetivar sua garantia. A segunda seção aborda o conceito de tolerância, que Habermas trabalha enquanto necessidade procedimental a partir de direitos subjetivos a iguais liberdades de ação, enquanto Forst o trabalha a partir de uma concepção como respeito ao outro, em que será essencial o princípio de justificação da justiça, amparado no uso público da razão. Ao final, as últimas considerações apontam para o fato de que Habermas mantém seu edifício teórico da década de 1990, trabalhando a possibilidade de tolerância e a garantia de direitos culturais a partir de procedimentos democráticos e de justiça política, nos quais normas e leis devem ser racionalmente aceitas em uma cultura política compartilhada. Já Forst busca um rumo prático-normativo, em que a razão prática requer pessoas razoáveis e autônomas moralmente, trabalhando a necessidade de justificação por via procedimental.

Palavras-chave: Direitos culturais. Justiça. Multiculturalismo. Tolerância.

\begin{abstract}
Through a reconstructive analysis of the political-juridical philosophy of Jürgen Habermas and Rainer Forst, as well as with the aid of secondary literature, the concepts of cultural rights and tolerance are analyzed. The purpose of the present research is to visualize how Habermas and Forst develop these concepts. To this end the article is divided into two sections, from an introductory justification of the investigation of the objectives outlined. The first section addresses the issue of cultural rights, their meaning, evolution, and how to enforce their guarantee. The second section addresses the concept of tolerance, which Habermas works as a procedural necessity from subjective rights to equal liberties of action, while Forst works on the concept of tolerance from a conception as respect, where the principle of justification of justice will be essential, supported by the
\end{abstract}


public use of reason. In the end, the final considerations point to the fact that Habermas maintains his theoretical edifice of the 1990s, working the possibility of tolerance and guarantee of cultural rights from democratic procedures and political justice, where norms and laws should be rationally accepted in a shared political culture, and Forst seeks a practical-normative course, where practical reason requires morally reasonable and autonomous persons, working the necessity of procedural justification.

Keywords: Cultural rights. Justice. Multiculturalism.Tolerance.

\section{Resumen}

A través de un análisis de la filosofía política y jurídica reconstructiva de Jürgen Habermas y Rainer Forst, así como con la ayuda de literatura secundaria, se examina los conceptos de los derechos culturales y la tolerancia. El objetivo de esta investigación es mostrar cómo Habermas y Forst desarrollan estos conceptos. Para ello el artículo se divide en dos secciones, partiendo de una justificación introductória de la investigación y de los objetivos establecidos. La primera sección aborda el tema acerca de los derechos culturales, su significado, evolución y la forma de aplicabilidad y garantía. La segunda sección aborda el concepto de tolerancia, que Habermas trabaja mientras la necesidad procedimental a partir de los derechos subjetivos a la misma libertad de acción, mientras que el concepto de tolerancia trabajado por Forst, parte de una concepción como respeto, en la cual será esencial el principio de justificación de la justicia, basada en el uso público de la razón. Al final, las consideraciones finales apuntan al hecho de que Habermas mantiene su edificio teórico de la década de 1990, trabajando la posibilidad de tolerancia y en la garantía de los derechos culturales a partir de procedimientos democráticos y de justicia política, donde las normas y las leyes deben ser racional aceptas en una cultura política compartida, y Forst busca un rumbo práctico-normativo, donde la razón práctica exige personas razonables y moralmente autónomos, proponiendo la necesidad de justificación por la vía procedimental.

Palabras clave: Derechos culturales. Justicia. Multiculturalismo. Tolerancia.

\section{Introdução}

Em sociedades altamente complexas marcadas pela transversalidade étnico-cultural e, ainda, pelas agudas diferenças sociais e de desenvolvimento entre o norte e o sul global retoma-se o debate acerca do conceito de tolerância, cujo debate ocupou os filósofos liberais do lluminismo, a 
exemplo das obras de Locke e Voltaire, e é uma das discussões presentes no liberalismo clássico.

Nas sociedades atuais não há mais a prevalência de um único credo ou, tão somente, das religiões monoteístas surgidas no Oriente Médio como o judaísmo, o cristianismo e o islamismo; as religiões da Índia, como o hinduísmo e o budismo; as religiões do extremo Oriente, como o confucionismo e o taoísmo; além das religiões africanas, as quais são tribais ou tradicionais, hoje também estão presentes nesses espaços e ativas. Soma-se também a isso o fato de que há muito "a moral" deixou de ser tradicional e se fragmentou ao longo da Modernidade a grupos e subgrupos étnicos e religiosos, constituindo-se, dessa forma, o que vem se convencionando chamar de sociedades pós-tradicionais ou pós-convencionais, termos muito utilizados pelo filósofo alemão Jürgen Habermas em várias de suas obras. Há que se frisar, no entanto, que a questão que envolve os direitos culturais e a tolerância não diz respeito mais, tão somente, à religiosidade, mas também às questões de etnia, diversidade cultural e de gênero, raça e grupos minoritários, os quais apresentam demandas por reconhecimento e inclusão.

Dentro desse quadro, a presente pesquisa tenciona desenvolver uma investigação a partir, principalmente, da obra de Habermas denominada Entre naturalismo e religião, publicada em 2007, no que diz respeito ao debate ali desenvolvido sobre a ideia dos direitos culturais e da tolerância. Pretende também traçar um paralelo com duas obras anteriores do autor, Direito e Democracia, de 1992, e A inclusão do outro, de 2002. Essas obras foram eleitas por dois motivos: primeiro, foi em Direito e Democracia (Faktizität und Geltung) que Habermas desenvolveu uma tese muito peculiar sobre o papel e o lugar do Direito e a função da democracia em uma sociedade contemporânea, o que o diferenciou neste aspecto quanto aos seus predecessores da Teoria Crítica, pois o Direito era visto de forma negativa até Adorno e Horkheimer; e, em segundo lugar, oferecer um comparativo em relação ao debate que Habermas traz em $A$ inclusão do outro acerca do reconhecimento, pois embora aborde neste texto uma 
discussão sobre o reconhecimento e os direitos coletivos, por meio de um diálogo com a obra do filósofo comunitarista canadense Charles Taylor, em Entre naturalismo e religião trata diretamente o tema dos direitos culturais, que, aliado ao tema da tolerância, parece oferecer um potencial teórico para uma tese mais aprofundada acerca de uma proposta de reconhecimento no Estado Democrático Constitucional.

Dessa forma, o presente estudo está dividido em duas seções. A primeira apresenta uma abordagem acerca da ideia dos direitos culturais, no sentido de analisar o que são, a quem devem pertencer e qual sua relação com os direitos coletivos e políticos. A segunda seção faz a leitura da forma pela qual Habermas trabalha o conceito de tolerância na obra Entre naturalismo e religião, com a pretensão de compreender como o mesmo pode ser pensado em sociedades pós-tradicionais ou pós-convencionais; ao mesmo tempo, tangencia um comparativo com a análise feita pelo também filósofo alemão Rainer Forst sobre a tolerância, sendo este, ao lado de Habermas e Axel Honneth, um dos principais nomes da Teoria Crítica nesta segunda década do século XXI.

Conforme observado por Rúrion Melo, ainda que seja notável a importância do nome de Franz Neumann para a primeira geração da Teoria Crítica, foi somente com Jürgen Habermas que se abriu uma nova perspectiva para a Teoria Crítica no aspecto da solidariedade a partir de reflexões sobre a moral, a política, o direito e a democracia. Rainer Forst é um dos mais influentes representantes da Teoria Crítica atual enquanto representante da quarta geração; seus trabalhos articulam uma teoria social e uma filosofia política normativa. Forst trabalha questões do pensamento político contemporâneo tais como justiça, tolerância, cidadania e direitos humanos, e em seu primeiro livro Contextos da Justiça entra de maneira pertinente no debate travado entre liberais e comunitaristas em 
questões como a neutralidade do direito, a concepção transcendental de pessoa racional e moral universal ${ }^{2}$.

\section{0 tema dos direitos culturais}

Atualmente, vive-se uma nova realidade político-social nas sociedades contemporâneas e nas relações sociais no interior dessas sociedades. Isso se dá não só pelas mudanças políticas ocorridas ao longo do século XX, mas principalmente em função da globalização mundial e de uma nova acomodação do capital por meio da transnacionalização dos mercados. Permanecem, ainda, situações de subdesenvolvimento em contraste com os Estados desenvolvidos do globo, naquilo que vem se convencionando chamar de relação norte versus sul global.

Nesse quadro, Alain Touraine sugere um novo tipo de mudança, qual seja, a da reivindicação dos chamados direitos culturais, os quais dizem respeito, primeiramente, às coletividades. A novidade, segundo o sociólogo francês, reside no fato de que grupos definidos em termos de nação, etnia ou religião, que só tinham existência na esfera privada, adquirem agora uma existência pública e, até mesmo, forte, quando o motivo é questionar sua pertença à determinada sociedade nacional ${ }^{3}$.Como consequência, vive-se o enfraquecimento das comunidades nacionais e o reforço das comunidades étnicas. Dessa forma, quanto aos direitos culturais:

(...)o mais importante é compreender bem que não se pode considerar os direitos culturais como uma extensão dos direitos políticos, na medida em que estes devem ser concedidos a todos os cidadãos, ao passo que os direitos culturais protegem,

\footnotetext{
2 MELO, Rúrion. Crítica e justificação em Rainer Forst. Cadernos de Filosofia Alemã, São Paulo, n. 22, jul./dez. 2013. Para análise de uma teoria crítica da justiça em Rainer Forst ver: FORST, Rainer. Contextos da justiça: filosofia política para além de liberalismo e comunitarismo. Tradução: Denilson Luís Werle. São Paulo: Boitempo, 2010.

3 TOURAINE, Alain. Um novo paradigma: para compreender o mundo hoje. Tradução: Gentil Avelino Titton. Petrópolis, RJ: Vozes, 2007.
} 
por definição, populações determinadas. (...) Trata-se aqui, na verdade, não mais do direito de ser como os outros, mas de ser outro. Os direitos culturais não visam apenas à proteção de uma herança ou da diversidade das práticas sociais; obrigam a reconhecer, contra o universalismo abstrato das Luzes e da democracia política, que cada um, individual ou coletivamente, pode construir condições de vida e transformar a vida social em função de sua maneira de harmonizar os princípios gerais da modernização com as "identidades" particulares. ${ }^{4}$

Como se nota, Touraine alerta para o fato de que os direitos culturais não podem ser compreendidos com direitos políticos, mas, sim, como uma característica importante destes direitos. Ressalta, ainda, que a reivindicação desses direitos também expõe a grandes perigos, porquanto dizem respeito sempre a uma população minoritária, levando ao risco de que todos os particularismos expõem as pessoas e, em uma palavra, "ameaçam o próprio princípio do viver juntos"s.

Ainda de acordo com Touraine, a passagem dos direitos políticos aos direitos sociais e, após, aos direitos culturais elevou a reivindicação democrática a todos os aspectos da vida social, bem como ao conjunto da existência e consciência individual. Nesse sentido, quanto maior for a coação imposta, quer seja pelo Estado quer seja pela própria maioria social a um indivíduo em todos os aspectos existenciais, mais se impõe a ideia de um indivíduo sujeito de direito, o qual resiste ou luta pelo direito de ser ele mesmo ${ }^{6}$.

Jürgen Habermas (2007, p. 306), na obra Entre naturalismo e religião, dedica um capítulo para a discussão que diz respeito à questão dos direitos culturais. Nesse sentido, o filósofo alemão argumenta que a ideia de iguais liberdades obriga os participantes do processo democrático a se concederem mutuamente os direitos exigidos pelo projeto de uma associação voluntária e autônoma de parceiros do direito, livres e iguais.

\footnotetext{
4 Ibidem, p. 171.

5 Ibidem, p. 171.

6 Ibidem, p. 172.
} 
Cabe perguntar em que se diferencia a reflexão de Habermas presente em Entre naturalismo e religião em relação às obras anteriores, especificamente em $A$ inclusão do outro e Direito e Democracia. Há uma mudança em seu aspecto teórico? Pode-se dizer que em relação ao núcleo central da teoria habermasiana, a resposta seja "não". Entretanto, questões no tocante ao conteúdo racional da moral, ao respeito para todos os sujeitos de direito, à solidariedade, ao reconhecimento e à inclusão, por exemplo, são conteúdos já tratados em $A$ inclusão do outro. Já em Direito e Democracia, estão presentes questões que dizem respeito a uma filosofia da justiça, aos direitos humanos, à democracia, à jurisdição constitucional, à política deliberativa e também à soberania popular.

Parece, todavia, que dois temas presentes na obra Entre naturalismo e religião, quais sejam, o debate sobre os direitos culturais e a tolerância, não foram abordados por Habermas em e $A$ inclusão do outro e Direito e Democracia. Em comum, as obras apresentam um diálogo e uma análise do liberalismo clássico e contemporâneo, especialmente a partir de Locke e Rawls, bem como com o republicanismo de Rousseau. Há, ainda, um diálogo constante com o comunitarismo de Charles Taylor. Por outro lado, também parece claro que Habermas pressupõe do leitor o conhecimento da sua tese, presente em Direito e Democracia, da associação voluntária e autônoma de parceiros do direito, livres e iguais.

Pode-se dizer, então, que Habermas passa a abordar a questão dos direitos culturais e da tolerância a partir do edifício teórico construído no início da década de 1990, não abrindo mão da ideia lançada em Direito e Democracia do direito enquanto medium da facticidade e validade. Com isso, o filósofo alemão irá desenvolver um debate acerca dos direitos culturais e também da tolerância muito a partir da tese defendida em Direito e Democracia, enquanto continuidade de sua filosofia político-jurídica. Então, Habermas continua muito presente no debate que tangenciam liberais e comunitários, abrindo espaço, inclusive para se poder tratar a partir de sua obra uma ideia de reconhecimento, tema já abordado por ele em $A$ inclusão do outro. 
Conforme esclarecimento de Catherine Audard (2006, p. 89), a natureza dos argumentos a favor de uma política de reconhecimento é moral e não cultural, sendo que

(...) no contexto pós-marxista, a exigência de reconhecimento de identidades culturais e pessoais distintas é um desafio às demandas de justiça social e de redistribuição em termos de igualdade e uniformização, demandas que até então estavam superadas de qualquer consciência de características culturais.

Audard (2006, p. 94) entende que "a demanda por justiça inclui, ao lado de outras dimensões, uma demanda por reconhecimento (...)", entendendo, ainda, ser essencial uma concepção democrática e inclusiva da justiça, a qual por sua vez deve compreender tal demanda por reconhecimento.

Nesse sentido, Habermas (2007, p. 311) argumenta que as éticas pós-modernas devem girar em torno da ideia de que "a pretensão da justiça humana só pode ser satisfeita plenamente no trato correto do não idêntico"7. Por isso, a ideia de direitos culturais e também políticas de reconhecimento são potenciais significativos para o fortalecimento da capacidade de autoafirmação de minorias discriminas, mormente quando

(...) o reconhecimento recíproco de membros com iguais direitos, o qual constitui o alvo do multiculturalismo, pressupõe relações interpessoais modificadas que se produzem pela via do agir comunicativo e do discurso e se harmonizam na esfera pública democrática, em última instância, mediante controvérsias políticas sobre a identidade ${ }^{8}$.

Ao contrário dos direitos sociais, "os direitos culturais têm de ser justificados tendo em vista as possibilidades da inclusão simétrica de todos os

\footnotetext{
7 HABERMAS, Jürgen. Entre naturalismo e religião: estudos filosóficos. Tradução: Flávio Beno Siebeneichler. Rio de Janeiro: Tempo Brasileiro, 2007.

8 Ibidem, p. 326.
} 
cidadãos"9. A partir daí fica a pergunta da forma pela qual se pode trabalhar a justificação dos direitos culturais (?), ao que Habermas defende a ideia de que:

(...) por meio da participação nas controvérsias nacionais sobre questões morais e éticas as comunidades religiosas podem promover uma autocompreensão pós-secular da sociedade em sua totalidade, a qual permite entrever uma continuidade vital da religião até mesmo num entorno que se encontra em franco processo de secularização ${ }^{10}$.

Nesta relação entre religião e Estado secular, Habermas abre espaço para conceituar e debater os direitos culturais, bem como a maneira pela qual se pode buscar a sua justificação, com vistas à inclusão de todos os cidadãos. No intuito de vislumbrar como Habermas conceitua e sugere a possibilidade de seu exercício, fato que será importante para justificação e, pois, garantia dos direitos culturais, a segunda seção oferece uma análise do referido conceito a partir de comparativos com obras anteriores e também interpretações de alguns comentadores.

\section{A tolerância}

Embora Habermas tenha abordado o tema do reconhecimento em A inclusão do outro, a matéria da tolerância não havia sido tratada da maneira que aparece em Entre naturalismo e religião, sendo dedicado um subcapítulo inteiro no capítulo IV da obra. Bem enfatizado pelo filósofo no início do capítulo é o fato de que a tolerância religiosa passou a ser um conceito do direito ao longo dos séculos XVI e XVII.

Em $A$ inclusão do outro, Habermas trabalha a questão do reconhecimento aliada à ideia do Estado Democrático de Direito, tratando a emancipação enquanto luta por reconhecimento. Nessa análise, os movimentos

\footnotetext{
9 Ibidem, p. 327.

10 Ibidem, p. 344.
} 
de emancipação não constituem um fenômeno unitário, mas um desafio segundo cada situação, sendo que quanto maior forem as diferenças religiosas, raciais ou étnicas, tanto maior será o desafio. Habermas ressalta neste estudo o fato de que do ponto de vista normativo não há Estado de direito sem democracia, ainda que "o princípio da soberania dos povos exige, ao inverso, o respeito aos direitos fundamentais sem os quais simplesmente não pode haver um direito legítimo: em primeira linha o direito a liberdades de ação subjetivas iguais (...)"1"1.

Note-se que, a proposta de uma concepção procedimental do direito e da democracia já está presente, portanto, em Direito e Democracia ressaltando que o processo democrático deve assegurar a autonomia privada e pública².

Entretanto, o tema da tolerância é abordado de forma direta a partir de Entre naturalismo e religião, no qual Habermas pressupõe a ideia de liberdades de ação subjetivas iguais, bem como do equilíbrio entre autonomia privada e pública.

Em seu estudo acerca da tolerância, Habermas alerta para a distinção que existe na língua inglesa quanto aos termos tolerance, que designa uma virtude ou disposição para o comportamento e, toleration, que constitui um ato jurídico. Já no alemão, Toleranz, designa as duas coisas, isto é, tanto uma ordem jurídica que garante a tolerância, como a virtude política do trato tolerante. Assim, trata-se de "um direito ao livre exercício da religião, o qual repousa no reconhecimento recíproco da liberdade de religião dos outros e que carrega após si um direito negativo de ser poupado de práticas religiosas estranhas" (HABERMAS, 2007, p. 280).

Dessa maneira, o princípio que aparece em Direito e Democracia fica assim estabelecido: "São válidas as normas de ação às quais todos os possíveis atingidos poderiam dar o seu assentimento, na qualidade

\footnotetext{
HABERMAS, Jürgen. A inclusão do outro: estudos de teoria política. Tradução: George Sperber e Paulo Astor Soethe. São Paulo: Loyola, 2002. p. 242-243.

12 HABERMAS, Jürgen. Faktizität und Geltung. Frankfurt am Main: Suhrkamp Verlag, 1992. p.112-118.
} 
de participantes de discursos racionais" (HABERMAS, 1992, p. 138). Por consequência, a institucionalização do direito no princípio discursivo se encontra da seguinte maneira: “[...] somente podem pretender validade legítima as leis jurídicas capazes de encontrar o assentimento de todos os parceiros do direito, num processo jurídico de normatização discursiva" (HABERMAS, 1992, p. 141). A partir daí, no momento em que o princípio discursivo toma a forma jurídica, nasce o princípio democrático.

Anteriormente, por meio da categoria procedimental discursiva, Habermas busca fundamentar racionalmente os direitos humanos, podendo-se falar, então, com propriedade, em uma teoria discursiva dos direitos humanos. De acordo com a interpretação de Arroyo, Habermas não tem uma definição específica de direitos humanos; uma das expressões com maior influência empregada pelo autor para referir-se ao núcleo da noção de direitos humanos é "o direito de todos os indivíduos a <<iguais liberdades >> de ação" (ARROYO, 2000, p. 20). Com isso, Habermas inclui nessa fórmula dois valores tradicionais: os ideais de liberdade e igualdade.

A teoria de Habermas vê os direitos humanos como meio de legitimidade para o processo legislativo, em que, segundo o autor, tal legitimidade apoia-se em um arranjo comunicativo, ao passo que os participantes de discursos racionais, ditos agora parceiros do direito, devem examinar o conteúdo controvertido de uma norma encontrando o assentimento de todos os possíveis atingidos pela mesma.

Amparado em sua já conhecida teoria discursiva do direito e da moral, Habermas (2007, p. 281) irá tratar da base do reconhecimento recíproco de regras do trato tolerante, dizendo que

\footnotetext{
(...) somente a concepção de liberdades iguais para todos e a fixação de um domínio de tolerância capaz de convencer simetricamente a todos os atingidos são capazes de extrair da tolerância o aguilhão da intolerância. Os possíveis atingidos têm de levar na devida conta perspectivas dos respectivamente "outros" caso pretendam chegar a um acordo sobre as condições
} 
sob as quais desejam exercitar tolerância recíproca apoiando-se no argumento de que todos merecem igual respeito.

Com isso, Habermas entende que os cidadãos somente irão especificar de forma consensual a fronteira entre a tolerância e a intolerância se tomarem suas decisões ante um modelo deliberativo, o qual leva as partes à assunção recíproca de perspectivas a igual ponderação de interesses ${ }^{13}$.

Habermas trabalha a ideia da tolerância enquanto conceito pós-secular sobretudo a partir da construção conceitual de Rainer Forst, que realizou seu doutoramento sob a supervisão do próprio Habermas no ano de 1993. Habermas chega a enunciar as concepções trabalhadas por Forst acerca da tolerância: "Rainer Forst contrapõe a concepção de permissão de uma autoridade que garante liberdades religiosas à concepção do respeito ao outro".14

Atualmente, na esteira da Teoria Crítica, um dos teóricos que vem explorando o tema da filosofia política e do direito, das teorias da justiça e, também, especificamente, da tolerância, é o filósofo alemão Rainer Forst, para quem, tolerância é "um conceito normativamente dependente, o qual, para que tenha determinado conteúdo (limites especificáveis), carece de recursos normativos adicionais que não sejam dependentes nesse mesmo sentido"15.

Forst localiza duas concepções acerca do termo tolerância: a primeira ele denomina de concepção como permissão, na qual a tolerância é uma relação entre uma autoridade ou uma maioria e uma minoria dissidente, diferente. Tolerância aqui significa que a autoridade (maioria) concede uma permissão aos membros da minoria para viverem de acordo com suas crenças, na condição de que aceitem a posição dominante da autoridade. Trata-se da concepção clássica, encontrada, inclusive, em documentos históricos, que são precedentes ilustrativos da política de tolerância.

\footnotetext{
13 Ibidem, p. 282.

14 Ibidem, p. 280.

15 FORST, Rainer. Os limites da tolerância. Novos Estudos Cebrap, São Paulo, n. 84, p. 18, 2009.
} 
A outra concepção de tolerância é a concepção como respeito, segundo a qual as partes tolerantes reconhecem uma a outra em um sentido recíproco:

Embora difiram notavelmente em suas convicções éticas a respeito do bem e do modo de vida legítimo e em suas práticas culturais, e sustentem em muitos aspectos visões incompatíveis, elas se respeitam mutuamente como moral e politicamente iguais, no sentido de que sua estrutura comum de vida social deve - na medida em que questões fundamentais de reconhecimento de direitos e liberdades e de distribuição de recursos estejam envolvidas - ser guiadas por normas que todos possam igualmente aceitar e que não favoreçam uma "comunidade ética" específica, por assim dizer ${ }^{16}$.

É na segunda concepção de tolerância que Forst concentra seus esforços, entendendo que é no respeito moral pelos outros, na condição de cidadãos iguais e com capacidade de traçar os limites com relação aos valores e às crenças e práticas julgadas erradas. A concepção denominada concepção como respeito busca encontrar os critérios para a determinação do conteúdo da tolerância, com auxílio de considerações da justiça procedimental.

Nesse sentido, Forst trabalha a ideia de que uma democracia reflexiva, isto é, aquela em que os sujeitos são conscientes de seus próprios princípios, deverá estar baseada no fundamental princípio da justificação da justiça, segundo o qual "todas as instituições que determinam a vida social e, por conseguinte, as vidas individuais dos cidadãos de modo considerável precisam ser justificáveis à luz de normas que os cidadãos não possam recíproca e genericamente rejeitar". Tal princípio resulta da reconstrução da pretensão de validade daquelas normas que devem ser reciprocamente justificáveis e genericamente legítimas, pretensão esta que precisa ser testada discursivamente.

A partir desse empreendimento, Rainer Forst dá um contorno à questão que envolve os limites da tolerância, no sentido de que seus limites

16 FORST, Rainer. Os limites da tolerância. Novos Estudos Cebrap, São Paulo, n. 84, p. 21, 2009. 
são atingidos quando um grupo tenta dominar os demais com visões que rejeitam a norma geral. Tal negação de direito à justificação é uma forma de intolerância, a qual não pode ser tolerada.

De acordo com Forst, "a concepção como respeito não implica separação estrita entre a "pessoa privada" ética e o citoyen político livre de toda particularidade; ao contrário, implica uma espécie de "igualdade qualitativa" de respeito igual e direitos iguais para pessoas com identidades ético-culturais diferentes" ${ }^{17}$.

Habermas, por sua vez, trata o tema da tolerância religiosa como sendo precursor do multiculturalismo e de uma coexistência, com iguais direitos e diferentes formas de vida no interior de uma comunidade constituída de modo democrático. A tolerância preserva a comunidade política pluralista de se dilacerar entre conflitos de visões de mundo opostas, de maneira que,

só pode praticar a tolerância quem tem argumentos subjetivamente convincentes para a rejeição de pessoas que seguem credos diferentes. Já que a tolerância não é indiferença, uma vez que indiferença por convicções e práticas estranhas e, inclusive, a avaliação do outro e de sua alteridade em termos meramente apreciativos anularia o objeto da tolerância ${ }^{18}$.

Assim, Habermas entende que o Estado secular somente poderá garantir tolerância, de maneira imparcial, quando for capaz de assegurar, na esfera pública política, que o pluralismo de cosmovisões se desenvolva alicerçado à base do respeito mútuo. Por outro lado, os direitos culturais, da mesma forma que o exercício da religião, "têm por objetivo garantir a todos os cidadãos um acesso equitativo às comunicações, tradições e

\footnotetext{
17 Ibidem, p. 24.

18 HABERMAS, Jürgen. Entre naturalismo e religião: estudos filosóficos. Tradução: Flávio Beno Siebeneichler. Rio de Janeiro: Tempo Brasileiro, 2007, p. 286-287.
} 
práticas de uma comunidade que eles julgam necessária para o exercício e a manutenção de sua identidade pessoal". ${ }^{19}$

Os denominados direitos culturais, na teoria de Habermas, devem ampliar-se de forma a garantir o acesso aos contextos da experiência, da comunicação e do reconhecimento, e, a partir disso, o envolvido pode articular uma compreensão de si mesmo, desenvolvendo e mantendo uma identidade própria. Assim, "os direitos culturais, exigidos e introduzidos à luz de uma 'política do reconhecimento', não podem ser entendidos como sendo naturalmente direitos coletivos. (...) trata-se, antes de tudo, de direitos subjetivos que garantem uma inclusão completa”20.

Forst ressalta que contemporaneamente paira uma crítica à concepção ocidental de direitos humanos, e que as sociedades ocidentais desenvolvidas trabalham tal concepção como ferramenta para o domínio político e cultural de outras sociedades. Forst entende ser indiscutível o fato de que o conceito de individualidade dos seres humanos surgiu no contexto de secularização e modernização da Europa; no entanto, propõe uma reformulação para uma concepção de direitos humanos, oferecendo uma base para o seu fundamento (FORST, 1999, p. 35).

A teoria da justiça de Forst oferece a ideia de um direito humano básico que é o direito à justificação, partindo da pretensão da sociedade de formar uma integração cultural. Esse direito é entendido como o núcleo moral imanente que constitui a fundação de uma concepção construtivista dos direitos humanos, explicada numa teoria discursiva moral ${ }^{21}$. Conforme interpretação de Denílson Werle, Forst entende que em uma sociedade democrática a tolerância depende do princípio de justificação pública que explicita quais razões para a tolerância são convincentes em determinados contextos de tolerância e conflito ${ }^{22}$. Dessa forma,

\footnotetext{
19 Ibidem, p. 298.

20 Ibidem, p. 299.

${ }^{21}$ Ibidem, p. 56.

22 WERLE, Denilson Luis. Justiça e democracia: ensaios sobre John Rawls e Jürgen Habermas. São Paulo: Singular: Esfera Pública, 2008, p. 153.
} 
o núcleo de uma fundamentação crítico-reflexiva do conceito de tolerância reside numa teoria da justificação prática, a qual afirma que a normatividade que reivindica validade universal e recíproca num determinado contexto deve poder ser fundamentada em comum. (...) A tolerância tem de ser pensada em conjunto com o conceito de democracia e de justiça política: sob o imperativo de não forçar indivíduos ou grupos a viverem sob normas e leis que não possam ser racionalmente justificadas, isto é, que não possam ser submetidas ao crivo do uso público da razão. Os limites da tolerância devem ser demarcados no plano horizontal dos cidadãos livres e iguais que se autocompreendem simultaneamente como destinatários e coautores do direito ${ }^{23}$.

Enquanto Rainer Forst trabalha o conceito de tolerância a partir de uma concepção como respeito ao outro, em que será essencial o princípio de justificação da justiça, baseado, portanto, na ideia do uso público da razão; Jürgen Habermas desenvolve uma defesa da tolerância como critério emancipatório apto à garantia dos direitos culturais, mediante a proposta de um agir comunicativo, amparado na ideia de iguais liberdades de ação, na qual a tolerância exige integração dos cidadãos do Estado, no contexto de uma cultura política compartilhada.

Em um comparativo da obra $A$ inclusão do outro com Entre naturalismo e religião, Habermas continua a trabalhar o tema da inclusão, do reconhecimento e das minorias étnicas e culturais. No entanto, Habermas não aborda em $A$ inclusão do outro, o tema dos direitos culturais de forma direta, como faz em Entre naturalismo e religião. Em A inclusão do outro, Habermas fala em direitos coletivos dos povos como condição necessária para a garantia dos direitos individuais, categorias que ele ressalta de forma diferente em Entre naturalismo e religião, em que os direitos culturais não podem ser

23 Ibidem, p. 354. 
tratados enquanto direitos coletivos, mas sim como direitos subjetivos que garantam inclusão, ao contrário da tese comunitarista de Charles Taylor. ${ }^{24}$

\section{Considerações finais}

A partir da pesquisa ora realizada, buscou-se vislumbrar a forma pela qual Habermas, reconhecido como representante da terceira geração da Teoria Crítica, trabalha o conceito de direitos culturais e de tolerância, conceitos estes importantes para as atuais sociedades do século XXI. Por óbvio, as conclusões ora apontadas seguem abertas à discussão e, também, à reconsideração, porquanto seja este o caráter epistemológico central de toda e qualquer produção do conhecimento. Dessa forma, podem-se elencar as seguintes notas terminativas:

I - Em meio ao debate atual que envolve as teses liberais e comunitaristas, a filosofia político-jurídica de Jürgen Habermas, oferece uma perspectiva para a reflexão acerca da questão polêmica e delicada que envolve os direitos culturais e a tolerância.

II - Habermas aborda a questão dos direitos culturais e da tolerância a partir do edifício teórico construído no início da década de 1990, não abrindo mão da tese lançada em Direito e Democracia da proposta do Direito enquanto medium da facticidade e validade. Com isso, o filósofo alemão desenvolve um debate acerca dos direitos culturais e também da tolerância mormente a partir da tese defendida em Direito e Democracia, enquanto continuidade de sua filosofia político-jurídica.

III - Por direitos culturais, Habermas entende serem direitos diferentes, tanto dos direitos sociais quanto dos direitos coletivos. São direitos subjetivos que devem garantir a inclusão completa, e os mesmos precisam ser justificados, tendo em vista as possibilidades da inclusão simétrica de todos os cidadãos. A justificativa dos direitos culturais deve se dar

24 TAYLOR, Charles. Multiculturalismo. Examinando a política de reconhecimento. Lisboa: Instituto Piaget, 1994. 
por meio da participação nas controvérsias nacionais sobre questões morais e éticas, assim, as comunidades religiosas podem promover uma autocompreensão de si mesmas.

IV - No que diz respeito à concepção de tolerância, pode-se sugerir que Habermas recebe de Rainer Forst o conceito pós-secular de tolerância, que Forst trabalha a partir de uma concepção como respeito, em que será essencial o princípio de justificação da justiça, baseado, portanto, na ideia de um uso público da razão. Habermas, por sua vez, desenvolve uma defesa da tolerância como critério emancipatório apto à garantia dos direitos culturais, mediante uma proposta de agir comunicativo, amparado na ideia de iguais liberdades de ação, em que a tolerância exige uma integração dos cidadãos do Estado, no contexto de uma cultura política compartilhada.

V - Quanto a uma pequena elucidação comparativa com a teoria de Rainer Forst, vislumbrou-se que ele busca um rumo prático-normativo, cuja concepção de razão prática requer pessoas razoáveis e autônomas moralmente, trabalhando a ideia da necessidade de justificação por via procedimental; enquanto Jürgen Habermas trabalha a aposta emancipatória ligada à tese da ação comunicativa, em uma proposta de consenso.

VI - Por derradeiro, sugere-se também conclusivamente que a leitura conjunta das obras de Habermas investigadas nesta pesquisa, quais sejam, Direito e Democracia, A inclusão do outro e Entre naturalismo e religião, oferecem pressupostos significativos para a reflexão acerca de uma teoria da justiça em Habermas, no que diz respeito às questões do reconhecimento moral e jurídico, da garantia dos direitos culturais, da inclusão e da tolerância, sendo esta última exercida enquanto garantia dos próprios direitos culturais.

\section{Referências}

AUDARD, Catherine. Cidadania e democracia deliberativa. Tradução: Walter Valdevino. Porto Alegre: EDIPUCRS, 2006. 
ARROYO, Juan Carlos Velasco. La teoria discursiva del derecho. Sistema jurídico y democracia em Habermas. Tradução: Mauro Victoria Soares. Madrid: Boletín Oficial del Estado, 2000.

FORST, Rainer. Os limites da tolerância. Novos Estudos Cebrap, São Paulo, n. 84, p. 15-29, 2009. https://doi.org/10.1590/s0101-33002009000200002

FORST, Rainer. The Basic Right to Justification: Toward a Constructivist Concepcion of Human Rights. Constellation, Oxford, v. 6, n. 1, p. 35-60, 1999.

HABERMAS, Jürgen. A inclusão do outro: estudos de teoria política. Tradução: George Sperber e Paulo Astor Soethe. São Paulo: Loyola, 2002.

HABERMAS, Jürgen. Entre naturalismo e religião: estudos filosóficos. Tradução: Flávio Beno Siebeneichler. Rio de Janeiro: Tempo Brasileiro, 2007.

HABERMAS, Jürgen. Faktizität und Geltung: Beiträge zur Diskurstheorie des Rechts und des demokratischen Rechtsstaats. Frankfurt am Main: Suhrkamp Verlag, 1992. https://doi.org/10.1007/978-3-531-90400-9 39

MELO, Rúrion. Crítica e justificação em Rainer Forst. Cadernos de Filosofia Alemã, São Paulo, n. 22, p. 11-30, jul./dez. 2013. https://doi.org/10.11606/ issn.2318-9800.v1i22p11-30

TAYLOR, Charles. Multiculturalismo. Examinando a política de reconhecimento. Lisboa: Instituto Piaget, 1994.

TOURAINE, Alain. Um novo paradigma: para compreender o mundo hoje. Tradução: Gentil Avelino Titton. Petrópolis, RJ: Vozes, 2007.

WERLE, Denilson Luis. Justiça e democracia: ensaios sobre John Rawls e Jürgen Habermas. São Paulo: Singular: Esfera Pública, 2008. 